\title{
Neurturin Exerts Potent Actions on Survival and Function of Midbrain Dopaminergic Neurons
}

\author{
Brian A. Horger, ${ }^{1}$ Merry C. Nishimura, ${ }^{1}$ Mark P. Armanini, ${ }^{1}$ Li-Chong Wang, ${ }^{1}$ Kris T. Poulsen, ${ }^{1}$ \\ Carl Rosenblad, ${ }^{6}$ Deniz Kirik, ${ }^{6}$ Barbara Moffat, ${ }^{2}$ Laura Simmons, ${ }^{3}$ Eugene Johnson Jr, ${ }^{5}$ Jeff Milbrandt, ${ }^{4}$ \\ Arnon Rosenthal, ${ }^{1}$ Anders Bjorklund, ${ }^{6}$ Richard A. Vandlen, ${ }^{2}$ Mary A. Hynes, ${ }^{1}$ and Heidi S. Phillips ${ }^{1}$ \\ Departments of ${ }^{1}$ Neuroscience, ${ }^{2}$ Protein Chemistry, and ${ }^{3}$ Molecular Biology, Genentech, South San Francisco, \\ California 94080, Departments of ${ }^{4}$ Pathology and ${ }^{5}$ Pharmacology, Washington University Medical School, St. Louis, \\ Missouri 63110, and ${ }^{6}$ Wallenberg Neurocentrum Institute, Lund, Sweden
}

Glial cell line-derived neurotrophic factor (GDNF) exhibits potent effects on survival and function of midbrain dopaminergic (DA) neurons in a variety of models. Although other growth factors expressed in the vicinity of developing DA neurons have been reported to support survival of DA neurons in vitro, to date none of these factors duplicate the potent and selective actions of GDNF in vivo. We report here that neurturin (NTN), a homolog of GDNF, is expressed in the nigrostriatal system, and that NTN exerts potent effects on survival and function of midbrain DA neurons. Our findings indicate that NTN mRNA is sequentially expressed in the ventral midbrain and striatum during development and that NTN exhibits survival-promoting actions on both developing and mature DA neurons. In vitro, NTN supports survival of embryonic DA neurons, and in vivo, direct injection of NTN into the substantia nigra protects mature DA neurons from cell death induced by 6-OHDA. Furthermore, administration of NTN into the striatum of intact adult animals induces behavioral and biochemical changes associated with functional upregulation of nigral DA neurons. The similarity in potency and efficacy of NTN and GDNF on DA neurons in several paradigms stands in contrast to the differential distribution of the receptor components GDNF Family Receptor $\alpha 1$ (GFR $\alpha 1$ ) and GFR $\alpha 2$ within the ventral mesencephalon. These results suggest that NTN is an endogenous trophic factor for midbrain DA neurons and point to the possibility that GDNF and NTN may exert redundant trophic influences on nigral DA neurons acting via a receptor complex that includes GFR $\alpha 1$.

Key words: neurturin; GDNF; dopaminergic; trophic; Parkinson's; nigrostriatal; 6-OHDA
Glial cell line-derived neurotrophic factor (GDNF) exhibits potent effects on the survival and function of midbrain dopaminergic neurons both in vitro and in vivo (Lin et al., 1993; Hoffer et al., 1994; Beck et al., 1995; Bowenkamp et al., 1995; Hudson et al., 1995; Sauer et al., 1995; Gash et al., 1996; Hebert et al., 1996). The GDNF receptor complex consists of two critical elements, both of which are expressed on nigral dopaminergic (DA) neurons: GDNF Family Receptor $\alpha 1$ (GFR $\alpha 1$ ), a glycosyl phosphatidylinositol (GPI)-linked protein that exhibits high-affinity binding for GDNF, and the tyrosine kinase ret (Durbec et al., 1996; Jing et al., 1996; Treanor et al., 1996; Trupp et al., 1997). Recent studies have revealed that neurturin (NTN), a homolog of GDNF, promotes the survival of GDNF-responsive populations of peripheral neurons (Moore et al., 1996) and that ret is a shared signaling component of the GDNF and NTN receptor complexes (Kotzbauer et al., 1996; Sanchez et al., 1996; Sanicola et al., 1997). Together with a recent report that NTN mRNA is present in the developing striatum (Widenfalk et al., 1997), these data suggest

Received Dec. 11, 1997; revised April 7, 1998; accepted April 15, 1998.

This work was supported in part by National Institutes of Health Grants RO1AG13729 and RO1AG13730 and by Grant 04X-3874 from the Swedish Medical Research Council. We thank Wayne Anstine for preparation of figures, Evelyn Berry for manuscript preparation, and Brigitte Devaux for helpful suggestions and coordination of resources.

B.H. and M.N. contributed equally to this manuscript.

Correspondence should be addressed to Dr. Heidi Phillips, Genentech, Inc., One DNA Way, South San Francisco, CA 94080.

Copyright (C) 1998 Society for Neuroscience $\quad 0270-6474 / 98 / 184929-09 \$ 05.00 / 0$ the possibility that NTN may influence the development or function of midbrain dopaminergic neurons.

The present study assessed the actions of NTN on midbrain DA neurons both in vitro and in vivo. In investigating the potential actions of NTN on midbrain DA neurons, we confirmed and extended previous observations on the distribution of mRNA for NTN and components of its receptor complex. In addition, we investigated whether NTN can influence the survival and function of midbrain DA neurons and examined the possibility that this factor might demonstrate efficacy in an animal model of Parkinson's disease.

\section{MATERIALS AND METHODS}

In situ hybridization. For in situ hybridization, mouse embryos were immersion-fixed overnight at $4^{\circ} \mathrm{C}$ in $4 \%$ paraformaldehyde, cryoprotected overnight in $15 \%$ sucrose, and frozen over liquid nitrogen. Postnatal day 1 (P1) and adult mouse brains were freshly frozen with powdered dry ice. All tissues were sectioned at $16 \mu \mathrm{m}$ and processed for in situ hybridization by a method described previously using $\left[{ }^{33} \mathrm{P}\right] \mathrm{UTP}-$ labeled RNA probes (Klein et al., 1997). Sense and antisense probes for NTN were synthesized from a 238-nucleotide DNA fragment of NTN that included nucleotides 351-588 (Kotzbauer et al., 1996) using T7 polymerase. Probes for GFR $\alpha 1$ and GFR $\alpha 2$ were as previously described (Klein et al., 1997). Autoradiographic exposure times were 7 weeks for NTN mRNA and 5 weeks for GFR $\alpha 1$ and GFR $\alpha 2$.

For combined immunocytochemistry and in situ hybridization, adult rats were perfused with $4 \%$ paraformaldehyde, and brains were removed and post-fixed overnight in the same fixative, cryoprotected overnight in $15 \%$ sucrose, frozen in dry ice, and sectioned at $35 \mu \mathrm{m}$. Free-floating sections were immunostained for tyrosine hydroxylase $(\mathrm{TH})$ using immunoperoxidase labeling. Briefly, sections were incubated for $1 \mathrm{hr}$ at $4^{\circ} \mathrm{C}$ with rabbit anti-TH primary antibody (Chemicon International, Te- 
mecula, CA; AB152, 1:500) followed by goat anti-rabbit IgG (Vector Laboratories, Burlingame, CA; $1 \mathrm{mg} / \mathrm{ml}, 30 \mathrm{~min}$ at $4^{\circ} \mathrm{C}$ ), and $\mathrm{ABC}$ elite reagent (Vector PK 6100, used at one-half of the manufacturer's recommended concentration, $30 \mathrm{~min}$ at $4^{\circ} \mathrm{C}$ ) each in $0.1 \mathrm{M}$ Tris $\mathrm{HCl}, \mathrm{pH} 7.5$, with $0.9 \% \mathrm{NaCl}$ and $0.1 \%$ gelatin. All incubations were separated by rinses in the same buffer system. For chromogenic reaction, a DAB substrate kit (Vector SK-4100, 2 min at $20^{\circ} \mathrm{C}$ ) was used. After immunostaining, sections were mounted onto slides, air-dried, and subjected to in situ hybridization for GFR $\alpha 2$ or GFR $\alpha 1$ as described above.

In vitro survival study. Cultures enriched for DA neurons of the ventral mesencephalon were obtained from embryonic day 14 (E14) rats (plug = E0). Tissues were dissected, treated with enzyme, triturated to a single cell suspension, and plated as previously described (Poulsen et al., 1994) with a few exceptions. Cells were plated on glass coverslips that were placed in 24-well plates. The concentration of insulin in the medium was decreased from 5 to $2.5 \mu \mathrm{g} / \mathrm{ml}$. All factors were added once at the time of plating. They were resuspended in $1 \mathrm{~mm} \mathrm{HCl}$ and diluted with media. After $4 \mathrm{~d}$ the cultures were fixed, stained for TH (Chemicon), and counted, as described previously (Hynes et al., 1994; Poulsen et al., 1994).

In vivo survival study: single intranigral injections of NTN or GDNF. Lesioning, administration of trophic factors, and analysis of cell survival were conducted as described previously, with minor modifications (Sauer et al., 1995). Forty-five female Sprague Dawley rats (Charles River Laboratories, Hollister, CA) weighing 230-250 gm received injections into both the right and left striata with $0.2 \mu \mathrm{l}$ of a $3 \%$ solution of fluorogold (FG; Fluorochrome Inc., Englewood, CO). Stereotaxic coordinates relative to bregma and dura were: anteroposterior (AP), $+0.5 \mathrm{~mm}$; mediolateral (ML), $\pm 2.8 \mathrm{~mm}$; and ventrodorsal (VD), $-4.5 \mathrm{~mm}$ (incisor bar set at 0 $\mathrm{mm}$ ). One week after FG administration, a single unilateral injection of 20 $\mu \mathrm{g}$ of 6-OHDA (Sigma, St. Louis, MO) in $2.8 \mu \mathrm{l}$ of saline, supplemented with $0.2 \mathrm{mg} / \mathrm{ml} \mathrm{L}$-ascorbic acid, was injected into the right striatum only, using the same stereotaxic coordinates. Seven days after lesioning, animals were divided into five groups: vehicle-treated $(n=16)$; NTN-treated $(1 \mu \mathrm{g}$, $n=7$; and $10 \mu \mathrm{g}, n=7)$; and GDNF-treated ( $1 \mu \mathrm{g}, n=7$; and $10 \mu \mathrm{g}, n=$ $8)$. Animals were anesthetized, and vehicle, NTN, or GDNF (1 or $10 \mu \mathrm{g})$ was injected into the right substantia nigra in a volume of $2 \mu \mathrm{l}$ of $1 \mathrm{~mm} \mathrm{HCl}$ (AP, $-5.2 \mathrm{~mm}$; ML, $-2.0 \mathrm{~mm}$; and VD, $-7.0 \mathrm{~mm}$ relative to bregma and dura; incisor bar set at $-3.3 \mathrm{~mm}$ ). All injections were made with a 26 gauge needle attached to a $10 \mu \mathrm{l}$ Hamilton syringe. All surgery was performed under aseptic conditions following National Institutes of Health animal care guidelines.

Four weeks after lesion, animals were deeply anesthetized and perfused with $4 \%$ paraformaldehyde. Brains were removed, placed into $4 \%$ paraformaldehyde at $4^{\circ} \mathrm{C}$ overnight for post-fixation, and then placed into $30 \%$ sucrose before freezing and sectioning. Sections were cut at $35 \mu \mathrm{m}$ using a freezing sliding microtome. Lesions were verified by TH staining of sections of the striatum. One animal (NTN-treated) was eliminated from the study, because it showed no evidence of a striatal lesion.

For cell counts, 10 serial sections through the substantia nigra were used. Five sections spaced at $70 \mu \mathrm{m}$ intervals were used for FG cell counts, and five alternating sections were processed for TH immunocytochemistry. The most anterior section of the area sampled corresponds to the anterior extent of the region in which the pars compacta of the substantia nigra is separated from the ventral tegmental area by the medial terminal nucleus of the accessory optic tract. For counts of FG+ cells, labeled cells exhibiting at least one neurite and polygonal shape in the substantia nigra were counted at $100 \times$ and $200 \times$ magnification using fluorescent illumination. Five sections adjacent to those used for FG counting were processed free-floating for $\mathrm{TH}$ immunocytochemistry using Chemicon anti-TH at a dilution of 1:1000 and the Vector ABC elite kit with very intense purple substrate. For $\mathrm{TH}+$ and $\mathrm{FG}+$ cell counts, both the lesioned-treated and unlesioned sides were counted. For each animal, the sum of the cells counted on all five sections of the lesioned side is expressed as a percentage of the total number of cells counted on all five sections of the unlesioned side. The mean percentages (lesioned vs unlesioned side) of $\mathrm{FG}+$ and $\mathrm{TH}+$ cells for each group are reported.

In vivo survival study: multiple intranigral injections of NTN. In a separate study, 6-OHDA-lesioned female Sprague Dawley rats (B \& K Universal, Stockholm, Sweden) weighing $225 \mathrm{gm}$ received repeated injections of NTN into the substantia nigra. In this multiple-injection paradigm, coordinates for FG administration were slightly modified (AP, $+1.0 \mathrm{~mm}$; ML, $\pm 3.0 \mathrm{~mm}$; and VD, $-5.0 \mathrm{~mm}$, relative to bregma and dura with incisor bar at $0 \mathrm{~mm}$ ). One week after FG injection, 6-OHDA was administered into the right striatum using the above coordinates. At the time of 6-OHDA administration, subjects were implanted with a 22 gauge guide shaft positioned in the scull bone dorsal to the substantia nigra. Over a $3 \mathrm{wk}$ period, starting $3 \mathrm{~d}$ after 6-OHDA administration, seven injections of $5 \mu \mathrm{g}$ of NTN in $2 \mu \mathrm{l}$ of $1 \mathrm{~mm} \mathrm{HCl}(n=6)$ or vehicle alone $(n=8)$ were administered every third day through the guide shaft using a 28 gauge injection cannula. The rats were killed $5 \mathrm{~d}$ after the last injection. To avoid repeated trauma to the substantia nigra, injections were made $\sim 1 \mathrm{~mm}$ dorsal to the pars compacta using the following coordinates, relative to bregma and dura: AP, $-5.0 \mathrm{~mm} ; \mathrm{ML},-2.5 \mathrm{~mm}$; and $\mathrm{VD},-6.0 \mathrm{~mm}$ (incisor bar set at $-3.3 \mathrm{~mm}$ ).

For histological evaluation, $30 \mu \mathrm{m}$ sections were cut through the substantia nigra. Three sections at the level of the medial terminal nucleus spaced at $120 \mu \mathrm{m}$ intervals were used for counting of FG+ cells, and three adjacent sections processed for $\mathrm{TH}$ immunocytochemistry were used for $\mathrm{TH}+$ cell counts. A third series was processed for FG and TH double labeling using Cy3-labeled secondary antibodies.

In vivo functional study. These experiments assessed the effects of NTN or GDNF on nonlesioned nigrostriatal dopaminergic functioning. Male Sprague Dawley (Charles River) rats $(280-300 \mathrm{gm} ; n=80)$ received a unilateral injection of one of three doses of NTN or GDNF $(0.1,1$, or $10 \mu \mathrm{g})$ or vehicle $(1 \mathrm{~mm} \mathrm{HCl})$ into the right striatum (flat skull coordinates relative to bregma and dura: AP, $+0.5 \mathrm{~mm}$; ML,$-2.8 \mathrm{~mm}$; and $\mathrm{VD},-4.5 \mathrm{~mm}$ ). The $2 \mu \mathrm{l}$ injection volume was delivered over $5 \mathrm{~min}$ using a 26 gauge $10 \mu \mathrm{l}$ Hamilton syringe. The cannula was left in place for an additional 3 min after the injection.

After a 4 or $5 \mathrm{~d}$ recovery period, the subjects injected with $1 \mu \mathrm{g}$ of NTN or GDNF, and vehicle-injected controls were tested for spontaneous locomotor activity using an automated photocell arena (San Diego Instruments). After a $30 \mathrm{~min}$ habituation period, subjects received a saline injection $(1 \mathrm{ml} / \mathrm{kg}$, i.p.) and were monitored for locomotor activity for 60 min. Twenty-four hours later, subjects were tested for amphetamineinduced $(1 \mathrm{mg} / \mathrm{kg}$, i.p.) locomotor activity using the same procedure.

One day subsequent to testing for amphetamine-induced locomotor activity (7 d after intrastriatal injections), tissue from selected brain regions was harvested. After decapitation, brains were removed rapidly and chilled in ice-cold saline for $15 \mathrm{sec}$. Brains were sliced into $1 \mathrm{~mm}$ coronal sections using a chilled stainless steel brain mold. Anterior, central, and posterior striatal samples were harvested from three sequential coronal sections using an 11 gauge punch. The central striatal sections included the intrastriatal injection site. Nucleus accumbens samples were harvested using a 13 gauge punch from coronal brain slices corresponding to the anterior striatum. Substantia nigra samples were collected using a 16 gauge punch centered in the medial pars reticulata and included a small portion of the pars compacta subregion.

The separation and quantification of DA and its major metabolite DOPAC was conducted using ion pair reverse-phase HPLC with electrochemical detection modified from that described previously (Horger et al., 1995). A C18 octadecyl silica $3 \mu \mathrm{m}$ minibore $(3.2 \times 100 \mathrm{~mm})$ column (Varian, Walnut Creek, CA) was perfused with a mobile phase consisting of (in $\mathrm{mm}$ ): 30 sodium citrate, 13.7 sodium phosphate, 2.3 sodium octane sulfonic acid, and 0.025 EDTA with $6.5 \%(\mathrm{v} / \mathrm{v})$ acetonitrile, $0.6 \%(\mathrm{v} / \mathrm{v})$ tetrahydrof uran, and $0.1 \%(\mathrm{v} / \mathrm{v})$ diethylamine, $\mathrm{pH} 3.1$, at a constant rate of $1 \mathrm{ml} / \mathrm{min}$. A Coulochem II (ESA, Chelmsford, MA) electrochemical detector applied a $-60 \mathrm{mV}$ potential to electrode 1 and a $+200 \mathrm{mV}$ potential to electrode 2 of a coulometric analytical cell (model 5011). Protein content was determined using the Bio-Rad (Richmond, CA) protein assay. Data from the injected side were analyzed as a percentage of values obtained from the noninjected hemisphere.

Recombinant GDNF and NTN. Rat GDNF was expressed in Escherichia coli and purified using a modification of a method described in earlier work (Henderson et al., 1994). The insoluble fraction after lysis of $E$. coli cells was suspended in $6 \mathrm{~m}$ guanidine hydrochloride buffer, $\mathrm{pH} 8$, and treated with sodium sulfite $(0.1 \mathrm{M})$ and sodium tetrathionate $(10 \mathrm{mM})$ to sulfonate the cysteine residues $\left(4^{\circ} \mathrm{C}\right.$ for $\left.16 \mathrm{hr}\right)$. After dialysis against $4 \mathrm{M}$ urea buffer and centrifugation, monomeric GDNF was partially purified by anion exchange chromatography and then refolded in a buffer containing $4 \mathrm{M}$ urea, $15 \%$ glycerol, $0.1 \mathrm{~m}$ phosphate, and $4 \mathrm{~mm}$ cysteine, $\mathrm{pH} 8$, at $4^{\circ} \mathrm{C}$. The GDNF dimer was then purified by anion exchange, cation exchange, and hydrophobic interaction chromatography. The final pool was dialyzed exhaustively against $1 \mathrm{~mm} \mathrm{HCl}$, aliquoted, and lyophilized.

Human NTN was expressed in E. coli as a histidine-tagged fusion protein. After lysis of the $E$. coli cells and S-sulfonation of the cysteine residues, the monomeric NTN was partially purified by metal affinity, cation exchange, and anion exchange chromatography. Refolding and isolation of dimeric NTN was similar to the method described above for GDNF. 

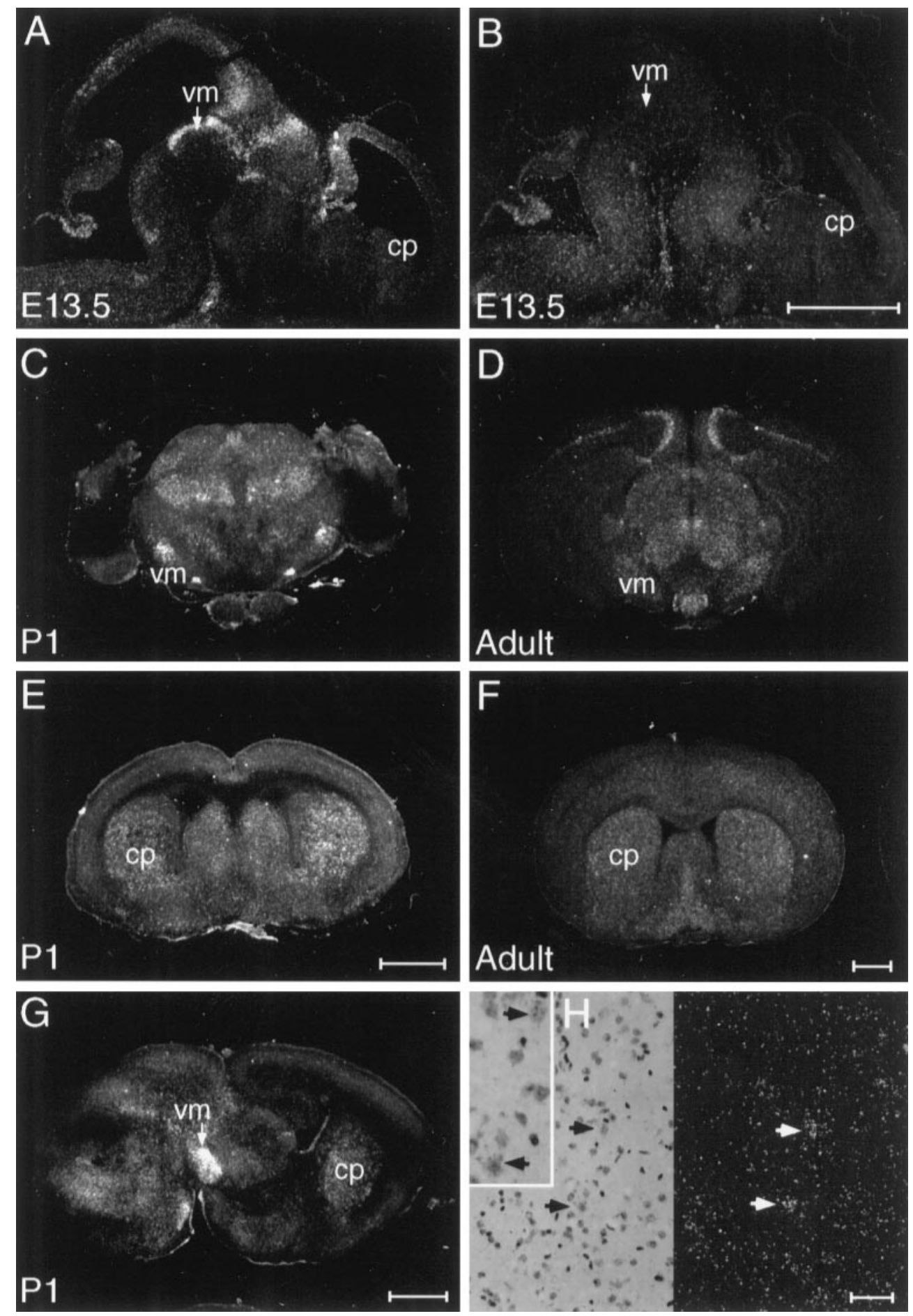

Figure 1. NTN mRNA appears sequentially in the ventral midbrain $(\mathrm{vm})$ and caudate putamen $(\mathrm{cp})$ of the developing mouse brain. Sections of E13.5 brain hybridized with antisense probe to NTN $(A)$ display strong hybridization in the ventral midbrain $(v m)$, whereas no hybridization is seen in the developing caudate putamen $(c p)$ above the background seen with sense strand control probe $(B)$. At P1, $(C, E, G)$ as well as in the adult brain $(D, F)$ hybridization is seen in both the ventral midbrain and caudate putamen. The signal in the adult caudate $(F, H)$ is associated with cells displaying a nuclear morphology characteristic of neurons. Scale bars: $B, E, F, 1 \mu \mathrm{m}$ (these apply to $A, C, D$, respectively); $G, 1 \mu \mathrm{m} ; H, 0.1 \mu \mathrm{m}$.

\section{RESULTS}

\section{NTN mRNA is expressed in the nigrostriatal system}

Examination of NTN mRNA distribution by in situ hybridization revealed NTN to be expressed within the developing rodent nigrostriatal system, appearing sequentially within the midbrain and striatum (Fig. 1). In the mouse, from E11.5 to E13.5, as dopaminergic neurons are differentiating, moderate to strong hybridization for NTN mRNA was observed in the ventral midbrain. During later embryogenesis and early postnatal life (E15.5 to P1), as nigral dopaminergic neurons extend axonal projections to their target areas, NTN expression was maintained at moderate levels within the ventral midbrain, and signal appeared at 
moderate levels within the striatum. In the adult brain, modest expression of NTN was maintained within the striatum, whereas only a weak, inconsistent hybridization signal appeared in the substantia nigra. The temporal pattern of NTN mRNA expression observed in the mouse nigrostriatal system bears similarity to previous reports of GDNF expression (Poulsen et al., 1994; Nosrat et al., 1996) and suggests that NTN may exert influences on developing or adult nigral DA neurons.

\section{NTN receptor components are expressed in and around nigral DA neurons}

Although GFR $\alpha 1$ mRNA is prominently expressed in the pars compacta of the substantia nigra and the ventral tegmental area, a more modest and diff use signal for GFR $\alpha 2$ is observed in the ventral midbrain (Fig. $2 A, B$ ). In sections stained for $\mathrm{TH}$, the majority of $\mathrm{TH}+$ nigral cells displayed equivocal signal for GFR $\alpha 2$, whereas intense hybridization was observed for GFR $\alpha 1$ in association with $\mathrm{TH}+$ cells of the substantia nigra (Fig. $2 C-I$ ). Strong signal for GFR $\alpha 2$ was, however, observed in regions immediately adjacent to midbrain DA neurons, including the dorsolateral aspect of the pars compacta of the substantia nigra, the medial and lateral terminal nuclei of the accessory optic tract, and the interpeduncular nuclei (Fig. 2C,D,G). Sections from animals killed at 1 week after intrastriatal 6-OHDA showed no evidence for upregulation of either GFR $\alpha 2$ or GFR $\alpha 1$ expression (data not shown).

\section{NTN promotes survival of DA neurons in vitro}

To determine whether NTN can act to promote survival of midbrain DA neurons, cultures of E14 rat ventral midbrain were investigated. This culture system revealed that, like GDNF, NTN can exert potent actions on the survival of TH-expressing cells from the developing midbrain (Fig. $3 A$ ). The potency and efficacy of NTN was similar to that observed for GDNF.

\section{NTN promotes survival of DA neurons in vivo after 6-OHDA exposure}

The ability of NTN to promote survival of embryonic rat midbrain DA neurons in vitro raised the possibility that NTN might be effective in promoting survival of DA neurons in the adult brain. In examining the ability of an intranigral injection of NTN to promote the survival and TH expression of DA neurons after striatal 6-OHDA administration, we observed that the efficacy of single injections of NTN is similar to that of comparable doses of GDNF (Fig. 3B,D,E). Our results indicated that a single intranigral injection of NTN, administered 1 week after the toxic insult, can lead to a significant sparing of nigral DA neurons, identified either by the retrograde tracer FG or by immunocytochemistry for TH (Fig. 3B,D,E).

To determine whether NTN may act on a subset of nigral DA neurons or on the entire population, we examined the ability of repeated injections of NTN to rescue DA neurons. Using the same lesion paradigm used above, repeated administration of NTN over the substantia nigra ( $5 \mu \mathrm{g}$ every third day for 3 weeks) resulted in a complete protection of $\mathrm{FG}+$ cells (Fig. 3C). The complete rescue of FG+ cells suggested that, like GDNF (Sauer et al., 1995), NTN was capable of influencing all nigral DA neurons. Although repeated administration of NTN is capable of promoting the survival of all retrogradely labeled nigral cells, the paradigm used here did not maintain $\mathrm{TH}$ expression of surviving neurons. In contrast to a single injection of NTN (Fig. 3B,D,E), repeated intranigral administration did not significantly increase the number of $\mathrm{TH}+$ neurons in the substantia nigra (Fig. $3 C$ ).

\section{NTN upregulates neurochemical and behavioral parameters of DA neuron function}

Locomotor activity was assessed after injection of $1 \mu \mathrm{g}$ of NTN and GDNF into the right striatum. As depicted in Figure $4 A$, locomotor activity after an intraperitoneal injection of saline was not altered by NTN or GDNF administration into the striatum. By contrast, locomotor activity induced by systemic administration of amphetamine (1 $\mathrm{mg} / \mathrm{kg}$, i.p.) was augmented after an intrastriatal injection of NTN or GDNF. As illustrated in Figure $4 B$, there was no difference between groups in the 30 min preinjection habituation period. After the amphetamine challenge, however, control subjects exhibited a moderate increase in activity counts peaking $20 \mathrm{~min}$ after injection. This amphetamineinduced increase in locomotor activity was significantly augmented in both NTN- and GDNF-injected subjects (Fig. 4B). Relative to controls, activity counts of NTN-injected subjects were significantly elevated at all postinjection time points except the first. In the GDNF-injected group a significant increase in locomotor activity was observed at the 30 , 40, and 50 min postamphetamine time points.

Because NTN and GDNF were administered unilaterally (right striatum), all neurochemical data are expressed as a percentage of the noninjected hemisphere. Table 1 lists the absolute values of DA (nanograms per milligram of protein) recovered from each brain region of control animals along with ratios of the major metabolite DOPAC to DA (DA utilization). Relative to controls, no significant differences in tissue content of DA were observed in any region after NTN or GDNF administration (data not shown). There were, however, significant differences in DA utilization observed in the NTN- and GDNF-administered groups relative to vehicle-injected controls. Individual one-way ANOVAs for NTN- and GDNF-injected subjects for each brain region revealed significant effects on DA utilization after intrastriatal NTN or GDNF in all three striatal regions and the nucleus accumbens (Fig. 4C). Post hoc analyses indicated dosedependent increases in DA utilization in each striatal region $(p<$ $0.05)$. In the nucleus accumbens, significant increases in DA utilization were observed after administration of 1 and $10 \mu \mathrm{g}$ of GDNF and $10 \mu \mathrm{g}$ of NTN $(p<0.5)$.

\section{DISCUSSION}

The potent actions of GDNF on midbrain DA neurons and its presence in the developing nigrostriatal system support the hypothesis that GDNF may serve as a trophic factor for midbrain DA neurons (Lin et al., 1993; Hoffer et al., 1994; Beck et al., 1995; Bowenkamp et al., 1995; Hudson et al., 1995; Sauer et al., 1995; Gash et al., 1996; Hebert et al., 1996); however, mice deficient in GDNF show no loss of these cells (Moore et al., 1996). These findings raise the possibility that DA neurons may be controlled during development by redundant trophic influences. Although other growth factors localized to the vicinity of developing DA neurons exhibit survival-promoting effects in vitro, actions of these factors in vivo have been disappointing (Hynes et al., 1994; Poulsen et al., 1994; Sauer et al., 1995; Jordan et al., 1997). Given the ability of NTN, a recently described homolog of GDNF, to promote survival of GDNF-responsive populations of peripheral neurons (Kotzbauer et al., 1996), we sought to determine whether NTN might exhibit trophic activities on midbrain DA neurons.

We report here that NTN expression is developmentally regulated in the nigrostriatal system and that NTN exhibits potent actions on the survival and function of midbrain DA neurons. Our results indicate that NTN mRNA is sequentially expressed in 

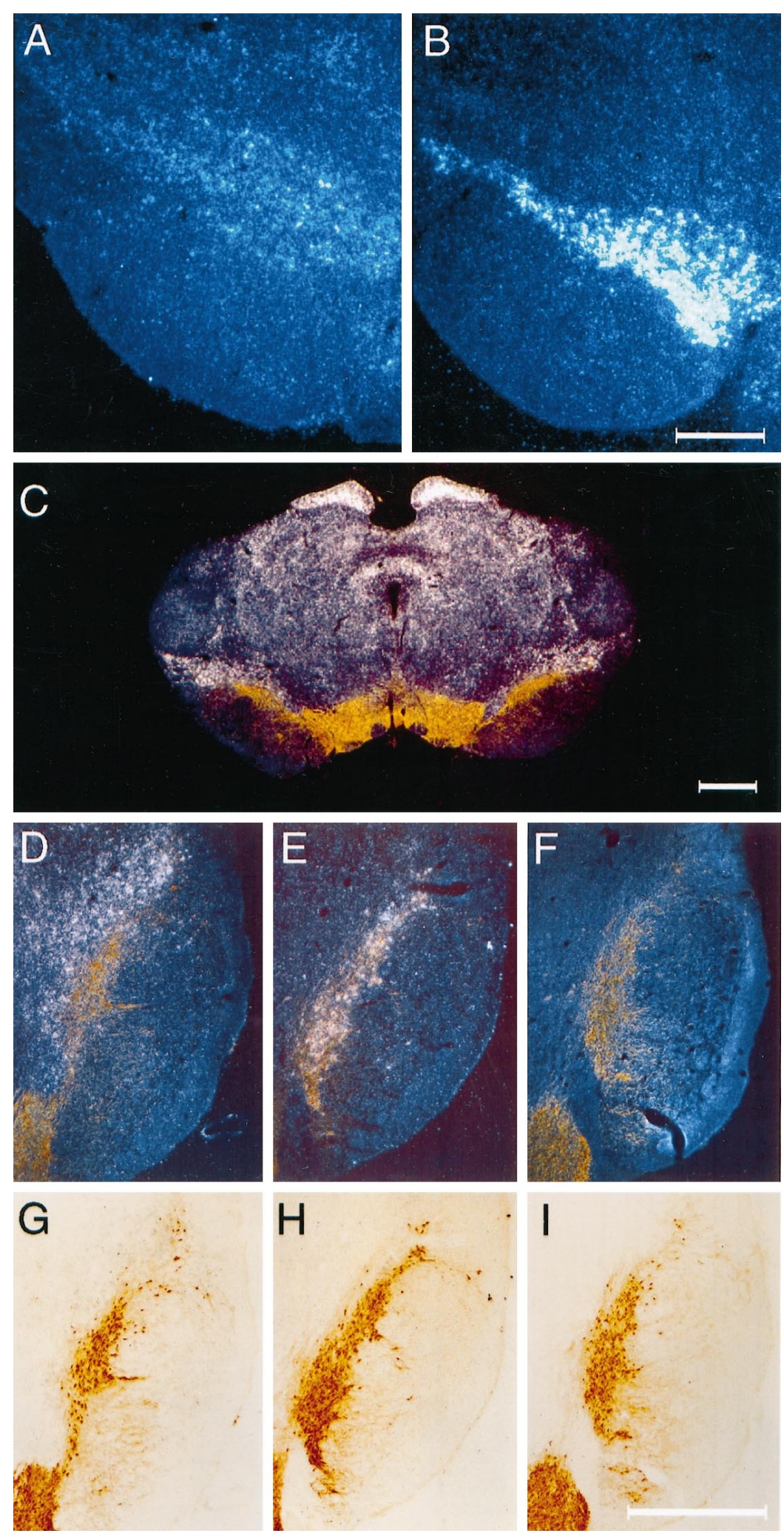

Figure 2. mRNA for GFR $\alpha 2$ is localized in the vicinity of nigral DA neurons. GFR $\alpha 2$ mRNA $(A)$ expression is much more diffuse and weak than GFR $\alpha 1(B)$ in the region of the pars compacta of the substantia nigra. Colocalization of $\mathrm{TH}$ staining (brown) and in situ hybridization for mRNA (white silver grains) for GFR $\alpha 2$ (C) reveals that the majority of GFR $\alpha 2$ expression in the adult ventral midbrain is not produced by DA neurons but by cells residing nearby. In particular, a band of GFR $\alpha 2$-expressing cells is seen in a zone that is dorsolateral to the pars compacta. $D-F$, Dark-field images of the same sections shown under bright-field illumination in $G-I$. All sections were immunostained for TH (brown). In situ hybridizations were performed for $\operatorname{GFR} \alpha 2(D, G), \operatorname{GFR} \alpha 1(E$, $H)$, and sense strand control probe $(F, I)$. Marginally more silver grains are seen for GFR $\alpha 2$ hybridization over $\mathrm{TH}+$ cells $(D, G)$ than in sections hybridized with a sense strand control probe to GFR $\alpha 1(F, I)$. Scale bars: $B, 0.5 \mu \mathrm{m}$ (applies to $A$ ); $C$, $I, 1 \mu \mathrm{m}(I$ applies to $D-I)$. the ventral midbrain and striatum, indicating that NTN protein is likely to be available to both developing and mature nigral DA neurons. Furthermore, we find in three separate paradigms that NTN is at least as potent and efficacious as GDNF in stimulating midbrain DA neuron survival or function. These results indicate that midbrain DA neurons are as responsive to NTN as to GDNF and point to the possibility that these homologous factors may act in concert to regulate the development and/or function of midbrain DA neurons.

Both in vitro and in vivo assays revealed NTN to be a potent factor in dopaminergic neuron cell survival. In direct comparisons, the potency and efficacy of NTN on survival of DA neurons 


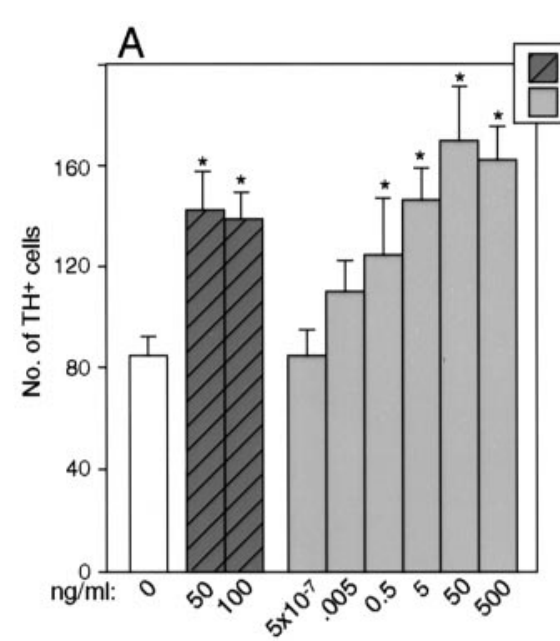

D
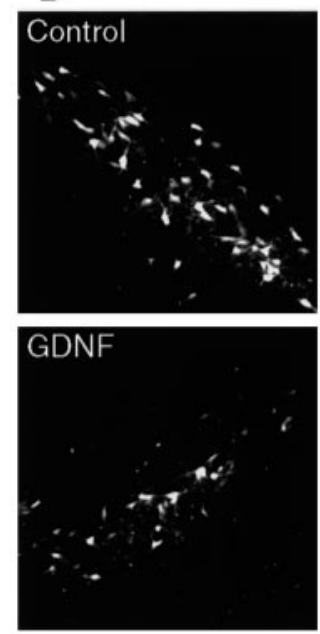
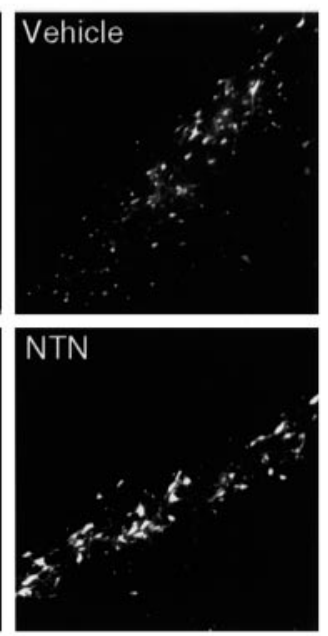

$B$

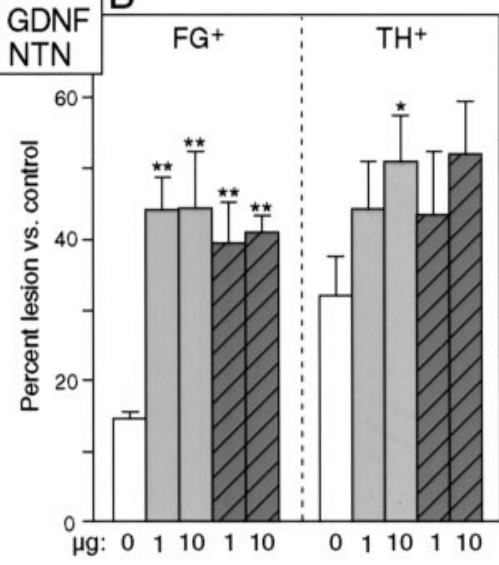

$\mathrm{E}$
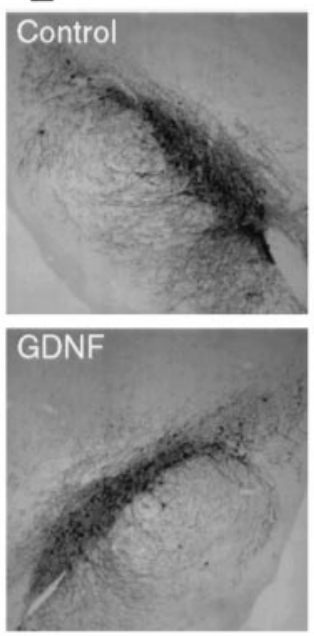

$\mathrm{C}$
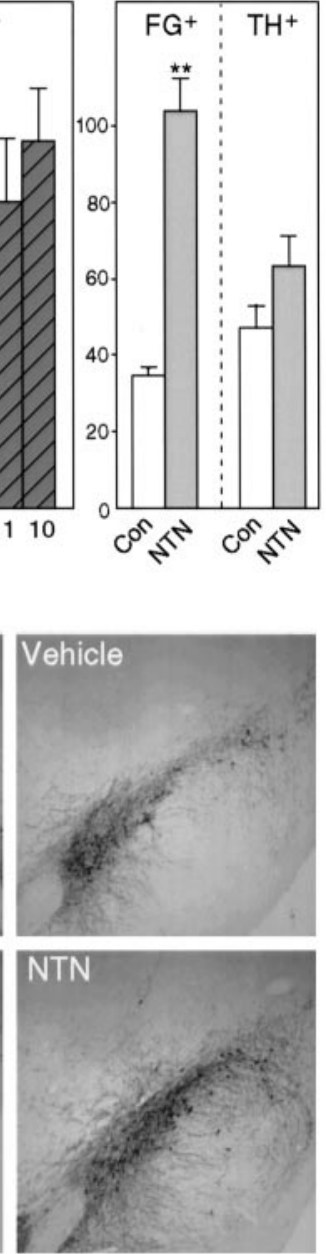

Figure 3. NTN promotes survival of midbrain DA neurons in vitro and in vivo. Values in $A-C$ represent mean \pm SEM; ${ }^{*} p<0.05 ; * * p<0.0001$ (vs control). $A$, NTN promotes survival of TH+ cells in cultures of E14 rat ventral mesencephalon. Survival responses to maximally effective concentration of NTN are very similar to those seen with optimal doses of GDNF. B, Single bolus injection of NTN can provide partial protection of FG+ or TH+ nigral cells after intrastriatal 6-OHDA administration. Single intranigral injections of 1 or $10 \mu \mathrm{g}$ of NTN or GDNF, administered 1 week after the toxic insult, produce comparable sparing of FG + cells after 6-OHDA. A single intranigral injection of $10 \mu \mathrm{g}$ of NTN can produce sparing of TH+ cells, whereas $1 \mu \mathrm{g}$ is not effective. Note the comparable effects of similar doses of GDNF and NTN at both doses on TH+ cells. $C$, Repeated administration of NTN rescued all FG + cells, but because a high proportion of the FG+ cells were TH-negative, the TH+ cell number was not significantly increased in the NTN-treated rats. In a series of double-labeled sections, the percentage of FG+ cells that expressed TH was reduced not only in the NTN-treated nigra but also in the controls treated with vehicle alone (from $80 \pm 3 \%$ on the nontreated intact side to $52 \pm 6 \%$ on the treated side), indicating a potential deleterious effect of repeated administration of the acidic, hypotonic vehicle (data not shown). $D$, Appearance of FG+ nigral cells after neurotoxic insult and rescue with GDNF or NTN. The top left panel represents a control substantia nigra (contralateral to 6-OHDA administration), whereas the top right panel depicts a vehicle-treated substantia nigra 4 weeks after ipsilateral intrastriatal 6-OHDA treatment. The lesioned nigra shows very few surviving neurons but many small cells of microglial morphology. The bottom panels demonstrate that a single bolus injection of $10 \mu \mathrm{g}$ of either NTN or GDNF protects the survival of many fluorogold-labeled neurons at 4 weeks after 6-OHDA administration. $E$, Appearance of TH+ cells after neurotoxic insult and rescue with GDNF or NTN. Top left and top right panels depict substantia nigra 4 weeks after 6-OHDA to the contralateral (left) or ipsilateral (right) striatum. The brain in the top right panel was treated by injection of vehicle into the pars compacta of the substantia nigra. Partial protection of TH-expressing cells is seen after a single bolus injection of $10 \mu \mathrm{g}$ of either NTN or GDNF into the pars compacta.

was indistinguishable from that observed for GDNF. In vitro, optimal concentrations of GDNF and NTN support the same number of midbrain DA neurons, and each agent showed maximal effects between 10 and $100 \mathrm{ng} / \mathrm{ml}$. To date, no clear additive effects of GDNF and NTN have been observed in this culture system. In vivo, a single administration of either NTN or GDNF led to a nearly threefold increase in surviving nigral cells (as detected by the retrograde tracer fluorogold) after intrastriatal injection of 6-OHDA. In addition, a single injection of NTN (10 $\mu \mathrm{g})$ significantly increased the number TH-expressing neurons in the substantia nigra. These findings indicate that NTN is capable of promoting the survival and maintenance of TH expression of both embryonic and adult nigral DA neurons.

Repeated intranigral injections of NTN effectively rescued all fluorogold-labeled cells, strongly suggesting that all nigral DA neurons are responsive to NTN. The failure of repeated nigral injections of NTN to promote protection of TH expression stands in contrast to the effects seen with a single bolus of NTN and to previous observations on GDNF (Sauer et al., 1995). It should be noted, however, that the current study used smaller quantities and less frequent injections of NTN $(7 \times 5 \mu \mathrm{g})$ than were previously used for GDNF $(14 \times 10 \mu \mathrm{g})$ and that the vehicle used differed in 

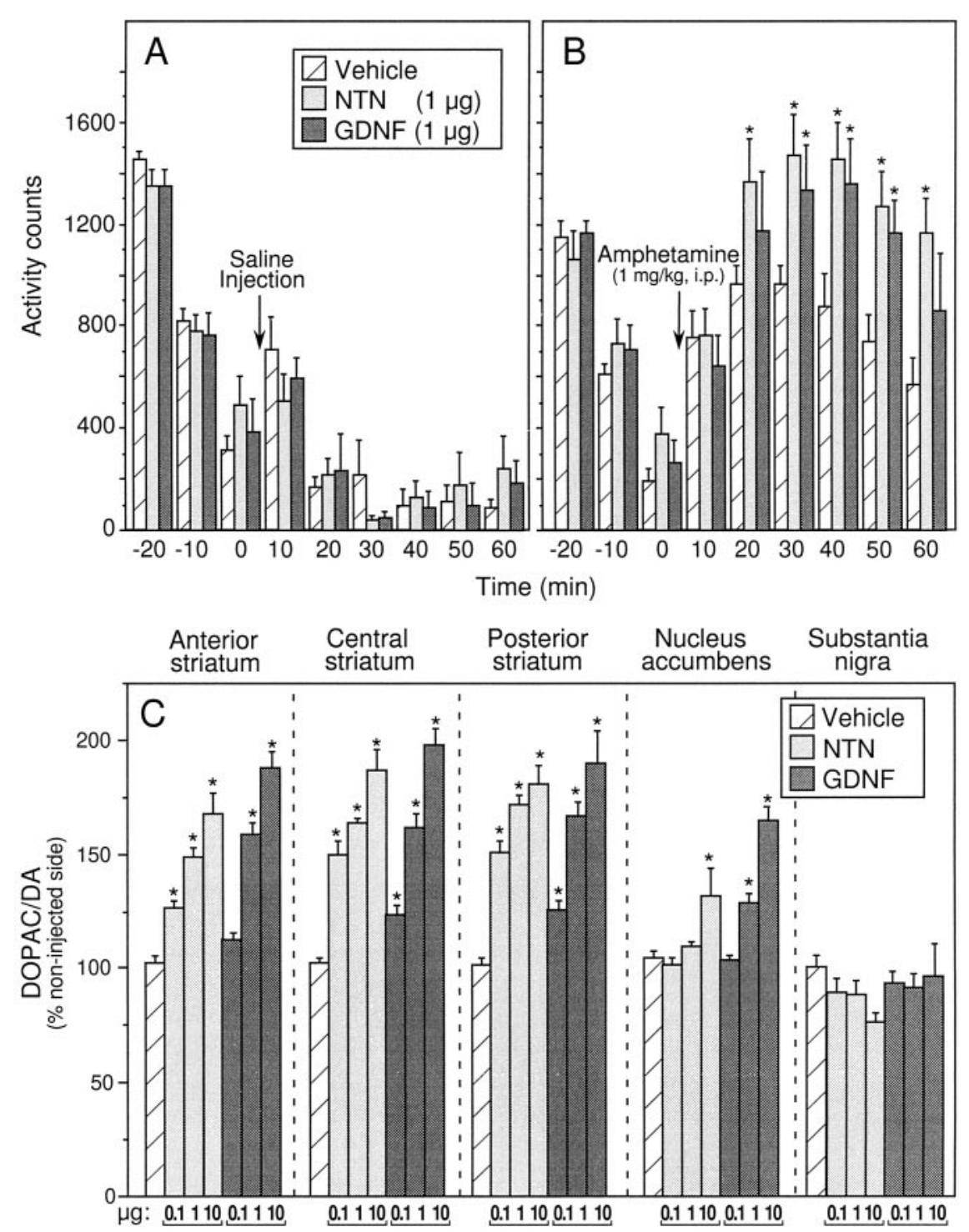

Figure 4. Intrastriatal injection of NTN or GDNF augments amphetamine-induced locomotor activity and increases striatal DA utilization. $A, B$, Injections of NTN or GDNF $(1 \mu \mathrm{g})$ into the right hemisphere do not significantly alter spontaneous open-field locomotor activity but do augment amphetamineinduced locomotor activity. $A, B$, Mean \pm SEM number of interrupted photocell beams $30 \mathrm{~min}$ before and $60 \mathrm{~min}$ after saline $(A)$ or amphetamine $(1 \mathrm{mg} / \mathrm{kg}$, i.p.) $(B)$ administration. Asterisks indicate significant differences from vehicle-injected controls $(p<0.05)$. $C$, Mean \pm SEM ratio of the metabolite DOPAC to DA in each brain region sampled 1 week after unilateral administration of NTN, GDNF, or vehicle in the right striatum. Data are depicted as percent of the noninjected (intact) hemisphere. Significant increases from vehicle-injected controls as determined by Fisher's post hoc analyses are indicated by an asterisk $(p<0.05)$. Except for the 1 and $10 \mu \mathrm{g}$ doses of NTN in the posterior striatum, individual doses within the same treatment group were significantly different from each other $(p<0.05)$. Subsequent comparisons revealed a significantly greater effect of the $0.1 \mu \mathrm{g}$ dose of NTN relative to the same dose of GDNF at all three striatal sites. In the nucleus accumbens, DA utilization was increased by both 1 and $10 \mu \mathrm{g}$ doses of GDNF, whereas only the highest dose of NTN reached significance. the two studies. In this regard, the possible deleterious effects of multiple injections of a nonphysiological (acid) vehicle on $\mathrm{TH}$ expression should not be overlooked (Fig. 3C, legend). Regardless of the actions of NTN on TH expression, the ability of NTN to produce a complete rescue of FG+ cells argues that NTN is capable of influencing the entire population of nigral DA neurons.

In addition to the survival-promoting effects of NTN, we observed that intrastriatal administration of NTN produced a dosedependent increase in DA utilization in the striatum. The biochemical effects of intrastriatal administration of NTN or GDNF were accompanied by an augmentation of amphetamine-induced locomotor activity, a behavioral index of functional activation of the nigrostriatal pathway. Although both NTN and GDNF produced an increase in striatal DA utilization, the data suggest that GDNF may be less efficacious than NTN at lower doses. Increased striatal DA utilization was significantly greater in response to the lowest dose of NTN tested $(0.1 \mu \mathrm{g})$ relative to the same dose of GDNF (Fig. 4). Further studies are needed to determine whether these results reflect differences in the responsiveness of nigral neurons to equivalent concentrations of the two growth factors or whether differences in distribution and stability of the proteins may account for the apparent differences in activity. Similarly, the greater neurochemical effects of GDNF in the nucleus accumbens relative to NTN may reflect differential responsivity of mesoaccumbal DA neurons or may reflect greater diffusion of GDNF from the intrastriatal injection site into the nucleus accumbens.

Recent studies have revealed that the GPI-linked protein GFR $\alpha 2$, (also referred to as $\operatorname{TrnR} 2, \mathrm{NTN}-\mathrm{R} \alpha$, or $\operatorname{GDNFR} \beta$ ), exhibits high-affinity binding for NTN and, together with the tyrosine kinase ret, can form a signaling complex for NTN (Baloh et al., 1997; Buj-Bello et al., 1997; Klein et al., 1997). Thus, the tyrosine kinase ret is a shared signaling component of the GDNF and NTN receptor complexes (Kotzbauer et al., 1996; Sanchez et al., 1996; Sanicola et al., 1997). These same studies have yielded mixed results about the potency with which NTN can interact with GFR $\alpha 1$ but indicate that under some conditions GFR $\alpha 1$ can participate in NTN signaling (Baloh et al., 1997; Buj-Bello et al., 1997; Klein et al., 1997; Sanicola et al., 1997). Localization studies to date have revealed the presence of both GFR $\alpha 1$ and ret on nigral DA neurons. The relationship of GFR $\alpha 2$ expression in the ventral midbrain to the location of DA neurons is less clear, but one report indicates that GFR $\alpha 2$ mRNA in the region of the 


\begin{tabular}{lcc}
\hline $\begin{array}{l}\text { Table 1. Tissue concentration of DA and DOPAC/DA in vehicle-treated } \\
\text { controls }\end{array}$ & \\
Brain region & DA (ng/mg protein) & DOPAC/DA \\
\hline Anterior striatum & & \\
$\quad$ Right & $209.2 \pm 6.4$ & $0.106 \pm 0.003$ \\
$\quad$ Left & $209.3 \pm 8.2$ & $0.104 \pm 0.002$ \\
Central striatum & $169.7 \pm 11.9$ & \\
$\quad$ Right & $183.1 \pm 11.3$ & $0.106 \pm 0.004$ \\
$\quad$ Left & $139.3 \pm 6.1$ & $0.103 \pm 0.002$ \\
Posterior striatum & $150.2 \pm 6.5$ & \\
$\quad$ Right & & $0.105 \pm 0.006$ \\
$\quad$ Left & $161.8 \pm 12.1$ & $0.098 \pm 0.003$ \\
Nucleus accumbens & $159.6 \pm 11.9$ & $0.133 \pm 0.004$ \\
$\quad$ Right & & $0.128 \pm 0.005$ \\
$\quad$ Left & $21.5 \pm 3.4$ & $0.218 \pm 0.100$ \\
Substantia nigra & $20.6 \pm 2.9$ & $0.222 \pm 0.110$ \\
$\quad$ Right & & \\
$\quad$ Left &
\end{tabular}

Values shown are mean \pm SEM amounts of DA (nanograms per milligram of protein) and the ratio of the metabolite DOPAC to DA (DA utilization) in the right (injected) and left (noninjected) hemispheres of vehicle-treated controls. No significant differences in DA content were observed after intrastriatal administration of NTN or GDNF. Changes in DA utilization relative to controls are depicted in Figure $4 C$.

substantia nigra is not associated with DA neurons (Widenfalk et al., 1997).

The present results confirm and extend previous observations on the distribution of GFR $\alpha 2$ in the ventral mesencephalon of the adult rat (Klein et al., 1997; Widenfalk et al., 1997). Consistent with previous reports, GFR $\alpha 1$ mRNA is prominently expressed in the pars compacta of the substantia nigra and the ventral tegmental area, whereas a more modest and diffuse signal for GFR $\alpha 2$ is observed in the region of the substantia nigra. Hybridizations performed on sections immunostained for the presence of $\mathrm{TH}$ reveals the presence of little, if any, GFR $\alpha 2$ mRNA in nigral DA neurons. These results are consistent with the observation that GFR $\alpha 2$ does not colocalize with $\mathrm{TH}+$ cells in the E14 rat ventral mesencephalon (Wang et al., 1997). Assuming that NTN signals via a complex involving GFR $\alpha 2$ and ret, the similarity of potency and efficacy of NTN and GDNF on DA neurons is difficult to reconcile with the relative lack of GFR $\alpha 2$ expression on DA neurons. Although we cannot rule out the possibility that NTN signals via low levels of GFR $\alpha 2$ present on the surface of DA neurons, our data point to the possibility that NTN might signal in vivo through GFR $\alpha 1$. Alternatively, it is possible that GFR $\alpha 2$ expressed by cells in the vicinity of nigral DA neurons may be presented to nigral DA neurons either by cell-cell contact or by shedding and diffusion of protein. The ability of soluble GFR $\alpha 2$ to act in vitro to confer responsiveness of motor neurons to NTN (Klein et al., 1997) supports this possibility.

The current findings indicate that NTN is expressed in the developing and adult nigrostriatal system and can exert potent influences on the survival and phenotypic expression of nigral dopaminergic neurons. Furthermore, the data indicate that NTN can upregulate nonlesioned intact nigrostriatal DA neurons. The potency and efficacy of NTN is equal or greater than that observed for GDNF on all measures of nigrostriatal survival or function investigated. Taken together, these results suggest that NTN might be an endogenous trophic factor for DA neurons and point to the possibility that NTN might be a useful agent to treat Parkinson's disease.

\section{REFERENCES}

Baloh RH, Tansey MG, Golden JP, Creedon DJ, Heuckeroth RO, Keck CL, Zimonjic DB, Popescu NC, Johnson Jr EM, Milbrandt J (1997) TrnR2, a novel receptor that mediates neurturin and GDNF signaling through Ret. Neuron 18:793-802.

Beck KD, Valverde J, Alexi T, Poulsen K, Moffat B, Vandlen RA, Rosenthal A, Hefti F (1995) Mesencephalic dopaminergic neurons protected by GDNF from axotomy-induced degeneration in the adult brain. Nature 373:339-341.

Bowenkamp KE, Hoffman AF, Gerhardt GA, Henry MA, Biddle PT, Hoffer BJ, Granholm AC (1995) Glial cell line-derived neurotrophic factor supports survival of injured midbrain dopaminergic neurons. J Comp Neurol 355:479-489.

Buj-Bello A, Adu J, Piñón P, Horton A, Thompson J, Rosenthal A, Chinchetru M, Buchman VL, Davies AM (1997) Neurturin responsiveness requires a GPI-linked receptor and the Ret receptor tyrosine kinase. Nature 387:721-724.

Durbec PL, Larsson-Blomberg LB, Schuchardt A, Costantini F, Pachnis V (1996) Common origin and developmental dependence on c-ret of subsets of enteric and sympathetic neuroblasts. Development 122:349-358.

Gash DM, Zhang Z, Ovadia A, Cass WA, Yi A, Simmerman L, Russell D, Martin D, Lapchak PA, Collins F, Hoffer BJ, Gerhardt GA (1996) Functional recovery in parkinsonian monkeys treated with GDNF. Nature 380:252-255.

Hebert MA, Van Horne CG, Hoffer BJ, Gerhardt GA (1996) Functional effects of GDNF in normal rat striatum: Presynaptic studies using in vivo electrochemistry and microdialysis. J Pharmacol Exp Ther 279:1181-1190.

Henderson CE, Phillips HS, Pollock RA, Davies AM, Lemeulle C, Armanini M, Simpson LC, Moffet B, Vandlen RA, Koliatsos VE, Rosenthal A (1994) GDNF: a potent survival factor for motoneurons present in peripheral nerve and muscle. Science 266:1062-1064.

Hoffer B, Hoffman A, Bowenkamp K, Huettl P, Hudson J, Martin D, Lin L, Gerhardt G (1994) Glial cell line-derived neurotrophic factor reverses toxin-induced injury to midbrain dopaminergic neurons in vivo. Neurosci Lett 182:107-111.

Horger BA, Elsworth JD, Roth RH (1995) Selective increases in dopamine utilization in the shell subdivision of the nucleus accumbens by the benzodiazepine inverse agonist FG 7142. J Neurochem 65:770-774.

Hudson J, Granholm A-C, Gerhardt GA, Henry MA, Hoffman A, Biddle P, Leela NS, Mackerlova L, Lile JD, Collins F, Hoffer BJ (1995) Glial cell line-derived neurotrophic factor augments midbrain dopaminergic circuits in vivo. Brain Res Bull 36:425-432.

Hynes MA, Poulsen K, Armanini M, Berkemeier L, Phillips H, Rosenthal A (1994) Neurotrophin-4/5 is a survival factor for embryonic midbrain dopaminergic neurons in enriched cultures. J Neurosci Res 37:144-154.

Jing S, Wen D, Yu Y, Holst PL, Luo Y, Fang M, Tamir R, Antonio L, Hu Z, Cupples R, Louis J-C, Hu S, Altrock BW, Fox GM (1996) GDNFinduced activation of the Ret protein tyrosine kinase is mediated by GDNFR- $\alpha$, a novel receptor for GDNF. Cell 85:1113-1124.

Jordan J, Bottner M, Schluesener HJ, Unsicker K, Krieglstein K (1997) Bone morphogenetic proteins: neurotrophic roles for midbrain dopaminergic neurons and implications of astroglial cells. Eur J Neurosci 9:1699-1709.

Klein RD, Sherman D, Ho W-H, Stone D, Bennett GL, Moffat B, Vandlen R, Simmons L, Gu Q, Hongo J-A, Devaux B, Poulsen K, Armanini M, Nozaki C, Asai N, Goddard A, Phillips H, Henderson CE, Takahashi M, Rosenthal A (1997) A GPI-linked protein that interacts with Ret to form a candidate neurturin receptor. Nature 387:717-721.

Kotzbauer PT, Lampe PA, Heuckeroth RO, Golden JP, Creedon DJ, Johnson Jr EM, Milbrandt J (1996) Neurturin, a relative of glial-cellline-derived neurotrophic factor. Nature 384:467-470.

Lin LF, Doherty DH, Lile JD, Bektesh S, Collins F (1993) GDNF: a glial cell line-derived neurotrophic factor for midbrain dopaminergic neurons. Science 260:1130-1132.

Moore MW, Klein RD, Fariñas I, Sauer H, Armanini M, Phillips H, Reichardt LF, Ryan AM, Carver-Moore K, Rosenthal A (1996) Renal and neuronal abnormalities in mice lacking GDNF. Nature 382:76-79.

Nosrat CA, Tomac A, Lindqvist E, Lindskog S, Humpel C, Strömberg I, Ebendal T, Hoffer B, Olson L (1996) Cellular expression of GDNF mRNA suggests multiple functions in side and outside the nervous system. Cell Tissue Res 286:191-207. 
Poulsen KT, Armanini MP, Klein RD, Hynes MA, Phillips HS, Rosenthal A (1994) Transforming growth factors- $\beta 2$ and 3 are potent survival factors for midbrain dopaminergic neurons. Neuron 13:1245-1252.

Sanchez MP, Silossantiago I, Frisen J, He B, Lira SA, Barbacid M (1996) Renal agenesis and the absence of enteric neurons in mice lacking GDNF. Nature 382:70-73.

Sanicola M, Hession C, Worley D, Carmillo P, Ehrenfels C, Walus L, Robinson S, Jaworski G, Wei H, Tizard R, Whitty A, Pepinsky RB, Cate RL (1997) Glial cell line-derived neurotrophic factor-dependent RET activation can be mediated by two different cell-surface accessory proteins. Proc Natl Acad Sci USA 94:6238-6243.

Sauer H, Rosenblad C, Björklund A (1995) GDNF but not TGF- $\beta 3$ prevents delayed degeneration of nigral dopaminergic neurons following striatal 6-hydroxydopamine-lesion. Proc Natl Acad Sci USA 92:8935-8939.

Treanor JJS, Goodman L, de Sauvage F, Stone DM, Poulsen KT, Beck KD, Gray C, Armanini MP, Pollock RA, Hefti F, Phillips HS, Goddard
A, Moore MW, Buj-Bello A, Davies AM, Asai N, Takahashi M, Vandlen R, Henderson CE, Rosenthal A (1996) Characterization of a multicomponent receptor for GDNF. Nature 382:80-83.

Trupp M, Belluardo N, Funakoshi H, Ibáñez CF (1997) Complementary and overlapping expression of glial cell line-derived neurotrophic factor (GDNF), c-ret proto-oncogene, and GDNF receptor- $\alpha$ indicates multiple mechanisms of trophic actions in the adult rat CNS. J Neurosci 17:3554-3567.

Wang L-C, Poulsen K, Milbrandt J, Johnson E, Hynes M (1997) GDNF and neurturin: receptor localization and survival activity for developing midbrain dopaminergic neurons. Soc Neurosci Abstr 23:889.

Widenfalk J, Nosrat C, Tomac A, Westphal H, Hoffer B, Olson L (1997) Neurturin and glial cell line-derived neurotrophic factor receptor- $\beta$ (GDNFR- $\beta$ ), novel proteins related to GDNF and GDNFR- $\alpha$ with specific cellular patterns of expression suggesting roles in the developing and adult nervous system and in peripheral organs. J Neurosci $17: 8506-8519$. 